ELECTROMOTIVE FORCES AND ELECTRODE POTENTIALS IN PURE AND MIXED SOLVENTS. II

BY F. S. MORTIMER AND J. N. PEARCE

The first systematic study of the electromotive forces in non-aqueous solvents was made by Jones. ${ }^{1}$ By using cells of the type:

$$
\mathrm{Ag}-\mathrm{AgNO}_{3} \text {.aq.- }-\mathrm{AgNO}_{3} \text {.non-aq.- }-\mathrm{Ag} \text {, }
$$

with the same concentration of the salt in each solvent, he had hoped to be able to calculate the degree of dissociation of the salt in the non-aqueous solvent. He found, however, that the solution pressure of a metal varies from solvent to solvent. By substituting the values found by Völlmer ${ }^{2}$ for the degree of dissociation of silver nitrate in ethyl alcohol, he calculated the solution pressure of silver in ethyl alcohol to be about one-fortieth of the value which it has in pure water.

Kahlenberg $^{3}$ measured the electrode potentials of ten different metals in o.Io $N$ solutions of their salts in about thirty different solvents. From his results he concludes that the solution pressure of a metal varies not only with the different solvents and their mixtures, but also with the nature of the dissolved salt.

The electrode potentials and electromotive forces of a number of cells containing solutions of salts of silver, lead, copper, mercury, cadmium and zinc were studied by Neustadt and Abegg. ${ }^{4}$ For solvents they used water, methyl alcohol, ethyl alcohol, acetone and pyridine. In all cases, the half cell, $\mathrm{Ag}-\mathrm{AgNO}_{3}{ }^{-}$, constitutes one-half of the cell. Since the potential differences in methyl alcohol, ethyl alcohol and acetone were found to be approximately equal to those in water,

${ }^{1}$ Zeit. phys. Chem., I4, 346 (1894).

2 Dissertation, Halle (1892).

${ }^{3}$ Jour. Phys. Chem., 3, 379 (1899).

${ }^{4}$ Zeit. phys. Chem., 69, 486 (I910). 
they believed that the solution pressures for any one metal in these four solvents are practically the same. The considerably lower values obtained for solutions in pyridine were attributed to an extremely low ionic concentration, due to association and the subsequent complex ionization of the silver nitrate in the pyridine solutions.

Getman $^{1}$ and Getman and Gibbons ${ }^{2}$ have measured the potentials of cadmium and zinc in alcoholic solutions of their salts, using the normal calomel electrode as the other half of the cell. Since the electrode potentials were found to become more negative as the concentration of the salt increases, they conclude that the applicability of the Nernst equation is very improbable. In a later investigation ${ }^{3}$ of the electrode potentials, transport numbers, and conductivities of solutions of silver nitrate in methyl alcohol, ethyl alcohol, acetone, and aniline, certain abnormalities were found which they attribute to the formation of complex solute-solvent compounds which dissociate more or less gradually with dilution.

The first attempt to measure the electromotive forces of concentration cells in alcoholic solutions were made by Wilson. ${ }^{4}$ His cells contained silver nitrate dissolved in methyl and ethyl alcohol and the measurements were made at $o$ and $25^{\circ}$. From the agreement between his results and the values calculated from the conductivities of the solutions he draws the conclusion that the Nernst equation can also be applied to non-aqueous solutions, yet admitting at the same time that the Nernst equation can hardly be recognized as giving more than approximate values.

Bell and Field ${ }^{5}$ measured the electromotive forces of concentration cells in water and ethyl alcoholic solutions of silver nitrate. The electromotive forces of concentration cells in aqueous solutions at $25^{\circ}$ were found to be in accord with the

\footnotetext{
1 Am. Chem. Jour., 46, II7 (I9II).

${ }^{2}$ Ibid., 48, I24 (I9I2).

${ }^{3}$ Jour. Am. Chem. Soc., 36, 1630 (I914).

4 Am. Chem. Jour., 35, 78 (1906).

5 Jour. Am. Chem. Soc., 35, 7 I5 (I9I3).
} 
Nernst equation for dilute solutions. Rearranging the equation for cells with transference to the form:

$$
\mathrm{K}=\frac{2 v}{u+v} \cdot \frac{\mathrm{RT}}{n f} \cdot \log _{e} \text { Io }=\frac{\mathrm{E}}{\log c_{1} / c_{2}},
$$

where $c_{1}$ and $c_{2}$ are the concentrations of the cation in the two solutions, they calculated the values of $K$. The values thus obtained for the aqueous solutions varied between 0.0560 and 0.0623 . For the ethyl alcoholic solutions the value of $\mathrm{K}$ for three combinations varied between 0.068 and 0.074 . Assuming the value 0.0623 for aqueous solutions and 0.074 for alcoholic solutions, they calculated the transport number of the $\mathrm{NO}_{3}-$ ion to be 0.523 and 0.62 , respectively. Since the value of $K$ varies so widely in these solvents, they conclude that the transport number of an ion is not independent of the concentration of the salt.

The first systematic study of electrode potentials and electromotive forces in mixed solvents was reported by Pearce and Farr. ${ }^{1}$ They determined the electromotive forces of concentration cells and the electrode potentials of silver against its ions for solutions of silver nitrate in water, methyl alcohol and ethyl alcohol, and in their binary mixtures at both $0^{\circ}$ and $25^{\circ}$. From the close agreement between the observed and calculated values for the electromotive forces it was shown that the Nernst equation can be applied not only to solutions in non-aqueous solvents, but also to solutions in the binary mixtures of these solvents. The electrode potentials were found to be relatively greatest in the methyl alcohol and smallest in the aqueous solutions, the corresponding values in ethyl alcohol occupying an intermediate position. In each solvent the electrode potential is highest in the most concentrated solution. These potential values decrease very rapidly with the first initial dilutions, while subsequently the decrease proceeds almost linearly as the concentration of the salt decreases. The electrode potentials in the binary mixtures of the alcohols obey the law of mixtures. In the binary mixtures

${ }^{1}$ Jour. Phys. Chem., I8, 729 (I9I4). 
of water with the two alcohols the electrode potentials increase slowly at first with the addition of the alcohol from the value in pure water up to mixtures containing about seventyfive percent of alcohol, and then more rapidly with further increase in the proportion of alcohol. They also determined the temperature coefficients of the electrode potentials, the solution pressure of silver in each of the pure solvents, and the heat of ionization in the pure solvents and in their fifty percent binary mixtures.

In the hope that still further light may be thrown upon the effect of solvent upon the electrochemistry of solutions, a fourth solvent-pyridine-has been added to the series. As a solvent pyridine occupies a position almost as unique as that of water. Its molecular structure is very different from that of the alcohols and water. It has a much lower dielectric constant, yet many salts dissolved in it give solutions of fairly good conducting power. The solution of salts in pyridine is generally accompanied by the liberation of a considerable quantity of heat. Salts crystallizing from pyridine solutions often separate with from one to several molecules of pyridine. Obviously, therefore, the salt molecules as well as the ions must be solvated to a considerable extent in solution.

\section{Materials and Solutions}

Water.-The conductivity water used in making all of the aqueous solutions was prepared according to the method of Jones and Mackay. ${ }^{1}$ It had a specific conductance of $0.6-\mathrm{I} .5 \times 10^{-6}$ mhos.

Ethyl Alcohol.-Ordinary 95 percent alcohol was allowed to stand over fresh quick-lime for two or three weeks. It was then decanted and distilled. The distillate was allowed to stand over anhydrous copper sulphate for one week and then redistilled. This distillate was refluxed with metallic calcium for ten hours and again distilled. Finally, it was refluxed for two hours with silver nitrate to remove aldehydes and other reducing agents. The distillate from this treatment

${ }^{1}$ Am. Chem. Jour., I9, 83 (1897). 
was collected and preserved in dry glass-stoppered bottles, being protected from the air during distillation by phosphorus pentoxide tubes. In each distillation a fractionating column was used and only that middle portion which passed over between $77.9^{\circ}$ and $78^{\circ}$ (uncor.) was retained.

Methyl Alcohol.-Kahlbaum's best grade was further purified in the same manner as the ethyl alcohol except that the treatment with quick-lime was omitted. Only that fraction of the distillate passing over between $64.9^{\circ}$ and $65 . \mathrm{I}^{\circ}$ was collected.

Pyridine.-The best grade of pyridine obtainable was allowed to stand over fused potassium hydroxide for several weeks. It was then decanted and distilled. That portion passing over between I I $5.3^{\circ}$ and II $5.7^{\circ}$ was collected and preserved in small glass-stoppered bottles, protected during the distilling process by a train of phosphorus pentoxide tubes.

The solvent mixtures were made up on a percentage basis by weight, the weights of the separate solvent components being accurate to o.I gram per liter.

Silver Nitrate.-Baker's "Analyzed" salt was further purified by recrystallization from a hot saturated solution of the salt in conductivity water. The crystals were filtered on a Büchner funnel, washed with ice-cold conductivity water, sucked dry and then heated for several hours in a toluol bath at $109^{\circ}$. The salt when perfectly dry was kept in dark bottles further protected by dark cloths.

Potassium Chloride.-Baker's "Analyzed" salt was further purified by precipitating a saturated solution by hydrogen chloride gas. The precipitate was filtered, washed with conductivity water, and dried in an air bath at $110^{\circ}$. The salt was always strongly heated before using.

Mercury.-The mercury used in preparing the calomel electrodes was purified by usual nitric acid method and the acid completely removed by repeated washing with conductivity water. It was then distilled under reduced pressure in a current of dry air.

Calomel.-Kahlbaum's best grade of mercurous chloride 
was washed repeatedly with a o.Io $N$ solution of potassium chloride after which it was preserved under a fresh sample of the same solution in dark bottles.

Solutions.-All solutions were prepared by direct weighing, or by the suitable dilution of freshly prepared solutions. They were made up to volume at $25^{\circ}$, and to avoid the possibility of decomposition occurring in the solutions, all electrometric measurements were made on the same day.

\section{Apparatus}

The apparatus used in this work was the same as that used by Farr. ${ }^{1}$ The $o^{\circ}$-bath was obtained by clean, finely crushed ice moistened with distilled water. The $25^{\circ}$-bath was kept in rapid circulation by a motor-driven mechanical stirrer. It was electrically heated and maintained at $25 \pm 0.0 \mathrm{r}^{\circ}$ by an electrically controlled temperature regulator.

Seven half-cells and two calomel electrodes were used simultaneously in this investigation. Each half-cell was fitted with a stopcock in the connecting tube. These were always kept closed except for very short intervals when measurements were being made. Loose plugs of filter paper inserted in the ends of the connecting tubes practically eliminated any possible diffusion even when the stopcocks were momentarily opened for potential readings. The middle vessel was so arranged that the connecting tubes of all the cells could be inserted simultaneously through tightly fitting rubber stoppers. With this arrangement the solutions were not unduly exposed and the measurements could be made on any combination by simply changing the wire leads and opening the stopcocks in the connecting tubes. A normal solution of ammonium nitrate was used in the middle vessel. It was assumed that this solution eliminates the diffusion potential. ${ }^{2}$

The calomel electrodes were prepared in the following manner: In the bottom of the electrode vessel was placed a large globule of mercury. This was next covered by an inti.

1 Loc. cit.

2 Ostwald-Luther: Messungen, 3rd Ed., p, 448. 
mately mixed paste of calomel and mercury moistened with o.Io $N$ solution of potassium chloride. Over this was placed a solution of $0.10 N$ potassium chloride which had been shaken with calomel and allowed to stand in contact with it until saturated. The single potential of the calomel electrode was calculated from the value given by Richards, ${ }^{1}$ the values taken being +0.5986 volt at $0^{\circ}$ and 0.6186 at $25^{\circ}$. These electrodes were renewed alternately every two weeks and were found to be immediately reproducible in most cases to within one-tenth of a millivolt. Upon standing for a day or longer they checked in every case to within 0.02 millivolt.

The electromotive forces were measured by means of a Wolff potentiometer in connection with a sensitive Leeds and Northrup "Type $H$ " wall galvanometer. In aqueous solutions it was easily sensitive to o.or millivolt, but the high resistances in non-aqueous solutions made it impossible to detect differences of less than o.I millivolt. A Cadmium-Weston cell which had been recently standardized against a similar element certified by the Bureau of Standards was used as a standard of reference. It had an electromotive force of I.Or 745 volts at $25^{\circ}$. While its temperature coefficient is practically negligible, it was kept at this temperature by insulating it in a deep beaker immersed in the $25^{\circ}$-bath.

The silver electrodes were prepared by fusing short pieces of silver wire into the ends of glass tubes. To the ends sealed into the glass were soldered copper wires, each the length of the glass tube. The tubes were then filled to within an inch of the top with hard paraffine which prevented the mercury, with which the contact was made, from amalgamating the silver electrode. Before using, the electrodes were plated by connecting them in series in a solution of potassium-silver cyanide. After a current of ten milliamperes had been passed for three hours, they were removed, rinsed with distilled water and then allowed to stand for forty-eight hours in contact with a button of pure silver under a pure aqueous solution of silver nitrate. Ten or twelve electrodes were thus prepared. The

${ }^{1}$ Zeit. phys. Chem., 24, 29 (1897). 
choice of the electrodes to be used was made in the following way: They were all grouped in a single cell containing a o. ro $N$ solution of silver nitrate which was in turn connected with a calomel electrode through an intermediate solution of ammonium nitrate. Only those electrodes were chosen which gave identically the same electromotive forces with the calomel.

It was observed early in the work that the electrode potential of a freshly prepared half-cell changes on standing. This change for any given electrode is most rapid at first, the rate of change then gradually decreasing to zero at equilibrium. In order to eliminate any errors from this source the whole battery of half-cells with their respective electrodes and solutions was set up and allowed to stand for at least one and one-half hours at constant temperature. This interval was repeatedly found to be sufficient for the attainment of equilibrium between the electrode and the solution.

\section{Theoretical}

There are four sources of electromotive force in any cell: the thermo-electric potential at the junction of the wire leads with the electrodes, the diffusion potential at the junction of the two solutions, and the two electrode potentials at the surfaces of contact between the electrodes and their respective solutions. The first of these is entirely eliminated by compensation, and it is assumed that the diffusion potential has been made negligible by the interposition of the r.o $N$ solution of nitrate. There are left for consideration, therefore, only the two electrode potentials.

According to the equation of Nernst, based on the osmotic theory of the cell, the electrode potential of a metal in contact with a solution of its ions is given by the expression

$$
\mathrm{E}=\frac{\mathrm{RT}}{n \mathrm{~F}} \cdot \log _{e} \frac{\mathrm{P}}{p},
$$

where $R$ represents the gas constant ( 1.985 cals.), $T$ the absolute temperature, $n$ the valence of the cation and $F$ the faraday ( 96540 coulombs). $P$ and $p$ represent, respectively, the solution pressure of the metal and the osmotic pressure of 
Electromotive Forces and Electrode Potentials, Etc. $\quad 283$

the cation in the solution, these pressures being measured in atmospheres.

Assuming the absence of a diffusion potential, the electromotive force $(\mathrm{E})$ of a concentration cell is equal to the difference between the two electrode potentials, or

$$
\mathrm{E}=\frac{\mathrm{R} T}{n \mathrm{~F}} \cdot \log _{e} \frac{p_{1}}{p_{2}} .
$$

Since the osmotic pressure of the ions is proportional to their concentrations, and since for normal electrolytes the ionic concentrations may be considered as approximately proportional to the equivalent conductivities of the solutions, then

$$
\frac{p_{1}}{p_{2}}=\frac{\alpha_{1} c_{1}}{\alpha_{2} c_{2}}=\frac{\lambda_{1} c_{1}}{\lambda_{2} c_{2}}
$$

where $c, \alpha$ and $\lambda$ represent the concentration of the salt, the degree of dissociation and the equivalent conductance, respectively. By substitution in Equation 2, we obtain

$$
\mathrm{E}=\frac{\mathrm{RT}}{n \mathrm{~F}} \cdot \log _{e} \frac{\lambda_{1} c_{1}}{\lambda_{2} c_{2}}
$$

The temperature coefficients have been calculated by means of the relation

$$
\frac{d \mathrm{E}}{d \mathrm{~T}}=\frac{\mathrm{E}_{2 \overline{\mathrm{a}}}-\mathrm{E}_{0}}{25 \cdot \mathrm{E}_{25}}
$$

The relation between the electrical and chemical energies of a cell is given by the well-known Helmholtz equation, viz.,

$$
\mathrm{E}=\frac{\mathrm{Q}}{\mathrm{F}}+\mathrm{T} \cdot \frac{d \mathrm{E}}{d \mathrm{~T}} \text {. }
$$

By rearranging this equation and multiplying by 0.2387 to transform joules into calories, we obtain the expression

$$
\mathrm{Q}=\mathrm{F}\left(\mathrm{E}-\mathrm{T} \cdot \frac{d \mathrm{E}}{d \mathrm{~T}}\right) \times 0.2337,
$$

where $Q$ is the heat of ionization.

Assuming that the osmotic pressure of the ions is given by the expression

$$
p=22.4 \cdot c \cdot x \cdot \frac{T}{273},
$$


the solution pressure of a metal may be calculated from. a transformation of Equation I, e.g.,

$$
\begin{gathered}
\log _{e} \mathrm{P}=\frac{\mathrm{E} n \mathrm{~F}}{\mathrm{RT}}+\log _{e}\left(22 \cdot 4 \cdot c \cdot \alpha \cdot \frac{\mathrm{T}}{273}\right) . \\
\text { Results }
\end{gathered}
$$

The results obtained are given in the following tables and curves:

\section{TABLE I}

Electrode Potentials in the Water-Pyridine Series

\begin{tabular}{|c|c|c|c|c|c|}
\hline $\mathrm{N}$ & $\begin{array}{l}\text { Ioo W } \\
\text { volts }\end{array}$ & $\begin{array}{c}75 \underset{\text { volts }}{\mathrm{W}}-25 \mathrm{P} \\
\mathrm{P}\end{array}$ & $\begin{array}{c}50 \mathrm{~W}-50 \mathrm{P} \\
\text { volts }\end{array}$ & $\underset{\text { volts }}{25} \underset{\mathrm{W}}{\mathrm{W}}-75 \mathrm{P}$ & $\begin{array}{l}\text { IOo P } \\
\text { volts }\end{array}$ \\
\hline I.O & I.05I3 & -1 & 0.7513 & 0.7002 & $0.6 \mathrm{II} 2$ \\
\hline 0.50 & I. $043^{\circ}$ & 0.7603 & 0.7026 & 0.6496 & 0.5866 \\
\hline O. IO & I. .0097 & 0.7075 & 0.6578 & 0.6070 & 0.5470 \\
\hline 0.05 & 0.9944 & 0.6820 & $0.637 \mathrm{I}$ & 0.5878 & 0.5367 \\
\hline 0.025 & 0.9774 & $0.665^{\circ}$ & 0.6178 & 0.57 I 4 & 0.5255 \\
\hline O.OI & 0.9578 & 0.6426 & 0.6023 & 0.5504 & 0.5066 \\
\hline 0.005 & 0.9403 & 0.6343 & 0.5928 & 0.5328 & $0.4^{853}$ \\
\hline
\end{tabular}

$25^{\circ}$

TABLE II

Electrode Potentials in the Water-Pyridine Series

$\mathrm{O}^{\circ}$

\begin{tabular}{l|c|c|c|c|c}
\hline \multicolumn{1}{c|}{$\mathrm{N}$} & $\begin{array}{c}\text { Ioo W } \\
\text { volts }\end{array}$ & $\begin{array}{c}75 \mathrm{~W}-25 \mathrm{P} \\
\text { volts }\end{array}$ & $\begin{array}{c}50 \mathrm{~W}-50 \mathrm{P} \\
\text { volts }\end{array}$ & $\begin{array}{c}25 \mathrm{~W}-75 \mathrm{P} \\
\text { volts }\end{array}$ & $\begin{array}{c}\text { Ioo P } \\
\text { volts }\end{array}$ \\
\cline { 2 - 6 } $\mathrm{I} . \mathrm{O}$ & $\mathrm{I} .0456$ & -1 & 0.7282 & 0.6836 & $0.58 \mathrm{IO}$ \\
0.50 & $\mathrm{I} .04 \mathrm{I} \mathrm{I}$ & 0.7332 & 0.6842 & $0.636 \mathrm{I}$ & 0.5678 \\
0.10 & $\mathrm{I} .0095$ & 0.7034 & 0.6324 & 0.5946 & 0.5296 \\
0.05 & $0.99 \mathrm{I} 3$ & 0.6739 & 0.6368 & 0.5758 & $0.52 \mathrm{I} 6$ \\
0.025 & 0.9820 & $0.658 \mathrm{I}$ & 0.6085 & 0.5630 & $0.508 \mathrm{I}$ \\
0.01 & 0.9625 & 0.6405 & 0.5973 & $0.542 \mathrm{I}$ & 0.4926 \\
0.005 & $0.947 \mathrm{I}$ & 0.6334 & 0.5866 & 0.5309 & 0.4746 \\
\hline
\end{tabular}

Mean Temperature Coefficients of Electrode Potentials

$=0.000045|+0.000430|+0.000762|+0.000771|+0.001293$

1 Insoluble. 
Electromotive Forces and Electrode Potentials, Etc. $\quad 285$

TABLE III

Electrode Potentials in the Ethyl Alcohol-Pyridine Series

\begin{tabular}{l|c|c|c|c|c}
\hline \multicolumn{1}{c|}{$\mathrm{N}$} & $\begin{array}{l}\text { Ioo E } \\
\text { volts }\end{array}$ & $\begin{array}{c}75 \mathrm{E}-25 \mathrm{P} \\
\text { volts }\end{array}$ & $\begin{array}{c}5 \text { o E-50 P } \\
\text { volts }\end{array}$ & $\begin{array}{c}25 \mathrm{E}-75 \mathrm{P} \\
\text { volts }\end{array}$ & $\begin{array}{l}\text { I0O P } \\
\text { volts }\end{array}$ \\
\hline $0.5 \mathrm{O}$ & -1 & 0.7986 & 0.6872 & 0.6380 & 0.5866 \\
0.10 & $\mathrm{I} .0826$ & 0.7348 & $0.639 \mathrm{I}$ & $0.592 \mathrm{I}$ & 0.5470 \\
0.05 & $\mathrm{I} .0686$ & 0.7084 & 0.6222 & 0.5790 & 0.5367 \\
0.025 & $\mathrm{I} .0592$ & 0.7007 & 0.6148 & 0.5655 & 0.5255 \\
0.01 & $\mathrm{I} .039 \mathrm{I}$ & $0.682 \mathrm{I}$ & 0.5906 & 0.5363 & 0.5066 \\
0.005 & $\mathrm{I} .0277$ & 0.6684 & 0.5667 & 0.5204 & 0.4853
\end{tabular}

TABLE IV

Electrode Potentials in the Ethyl Alcohol-Pyridine Series

\begin{tabular}{|c|c|c|c|c|c|}
\hline $\mathbf{N}$ & $\begin{array}{l}\text { 100 } \mathrm{E} \\
\text { volts }\end{array}$ & $\begin{array}{c}75 \underset{\text { volts }}{\mathrm{E}-25} \mathrm{P} \\
\text { P }\end{array}$ & $\begin{array}{c}50 \mathrm{E}-50 \mathrm{P} \\
\text { volts }\end{array}$ & $25 \underset{\text { volts }}{\mathrm{E}-7.5 \mathrm{P}}$ & $\begin{array}{l}\text { roo } \mathrm{P} \\
\text { volts }\end{array}$ \\
\hline 0.50 & -1 & 0.7698 & $0.662 \mathrm{I}$ & 0.6190 & 0.5678 \\
\hline 0.10 & . . 0696 & $0.7 \mathrm{r} 44$ & 0.6195 & $0.574 \mathrm{I}$ & 0.5296 \\
\hline 0.05 & I. .057 I & 0.6866 & 0.6036 & 0.5603 & 0.5216 \\
\hline 0.025 & I.0466 & 0.6739 & $0.595^{2}$ & 0.5473 & $0.508 \mathrm{I}$ \\
\hline $0.0 \mathrm{I}$ & I. $025^{\mathrm{I}}$ & 0.6583 & 0.5726 & $0.5^{108}$ & 0.4926 \\
\hline 0.005 & I.OI3I & 0.6397 & $0.55 \mathrm{I} 2$ & 0.5083 & 0.4746 \\
\hline
\end{tabular}

Mean Temperature Coefficients of Electrode Potentials

+0.000506 $|+0.001457|+0.001280|+0.001295|$ +o.001293

TABLE V

Electrode Potentials in the Methyl Alcohol-Pyridine Series

\begin{tabular}{|c|c|c|c|c|c|}
\hline$N$ & $\begin{array}{l}\text { IOO M } \\
\text { volts }\end{array}$ & $\underset{\text { volts }}{75}$ & $\underset{\text { volts }}{5 \circ \mathrm{M}-50 \mathrm{P}}$ & $\underset{\text { volts }}{25 \mathrm{M}}$ & $\begin{array}{l}\text { IOO } \mathrm{P} \\
\text { volts }\end{array}$ \\
\hline 0.50 & $\longrightarrow^{1}$ & 0.8105 & 0.7177 & 0.6386 & 0.5866 \\
\hline o. IO & I. 0975 & 0.7306 & $0.654 \mathrm{I}$ & $0.59 \mathrm{II}$ & 0.5470 \\
\hline 0.05 & I.0799 & 0.7145 & 0.6369 & 0.5690 & 0.5367 \\
\hline 0.025 & I.0707 & 0.6959 & 0.6201 & 0.5520 & 0.5255 \\
\hline 0.01 & I. 0507 & 0.6766 & 0.6000 & 0.5426 & 0.5066 \\
\hline 0.005 & I. 0286 & $0.66 \times 2$ & 0.5834 & 0.5280 & 0.4853 \\
\hline
\end{tabular}

1 Insoluble. 
TABLE VI

Electrode Potentials in the Methyl Alcohol-Pyridine Series

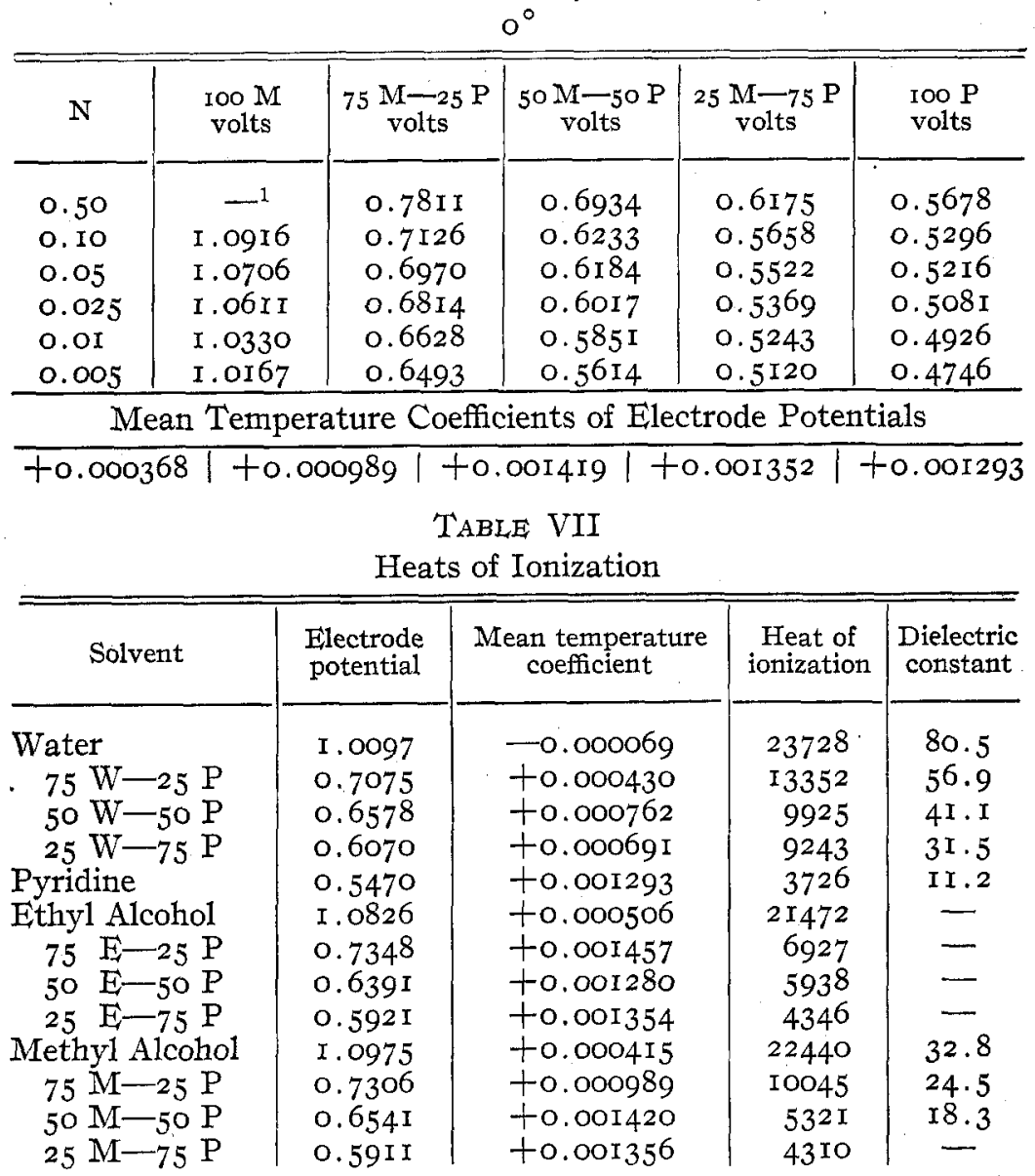

TABLE VIII

Solution Pressures in the Pure Solvents

\begin{tabular}{l|l}
\hline \hline Solvent & Solution pressure \\
\hline Water & $2.46 \times 10^{-17}$ \\
Ethyl Alcohol & $2.02 \times 10^{-18}$ \\
Methyl Alcohol & $3.55 \times 10^{-19}$ \\
Pyridine & $1.77 \times 10^{-10}$
\end{tabular}

${ }^{1}$ Insoluble. 


\section{Discussion}

In the accompanying tables (I-VI) are given the potentials of the silver electrode measured against solutions of its ions in water, methyl alcohol, ethyl alcohol and pyridine, and in the binary mixtures of pyridine with each of the other solvents. From these tables and the corresponding curves (Plate II) it is to be observed that the electrode potentials of silver are much higher for solutions in water and the two alcohols than for equivalent concentrations in pyridine. Furthermore for any given concentration of silver nitrate the electrode potential increases with the decrease in the proportion of pyridine in the solvent mixture. This increase is very gradual until seventy-five percent of the pyridine has been replaced by the second solvent. For water-pyridine mixtures the initial increase is apparently a linear function of the percent of water present in the mixture. With further decrease in the proportion of pyridine there is a rapid increase in the value of the electrode potential up to its value in the second solvent.

These electrode potential-solvent curves show a striking resemblance to the dielectric constant-solvent curve plotted for the same solvent mixtures. The dielectric constants of the water-pyridine and methyl alcohol-pyridine mixtures were determined by the Drude-Schmidt method and the values are given in Table VII. In both mixtures the dielectric constant increases rather slowly at first with the decrease in the proportion of pyridine up to mixtures containing about seventyfive percent of the second solvent and then more rapidly with further decrease in the proportion of pyridine. According to the law of Dutoit and Aston those solvents which have the highest dielectric constants are those in which electrolytic dissociation takes place to the greatest extent. Thus for a given concentration of silver nitrate ionization should increase with a decrease in the pyridine content of the solvent mixture. For metals whose electrodes are electropositive to solutions of their ions this should mean a corresponding increase in the electrode potential, and such is the case in the solvents studied.

The curves for the water-pyridine series show also a 
striking resemblance to the curve obtained by Hartley, Thomas and Appleby ${ }^{1}$ for the surface tention of the same series of mixtures. Whether or not any relation exists between surface tension and the electrode potential is a question still unanswered.

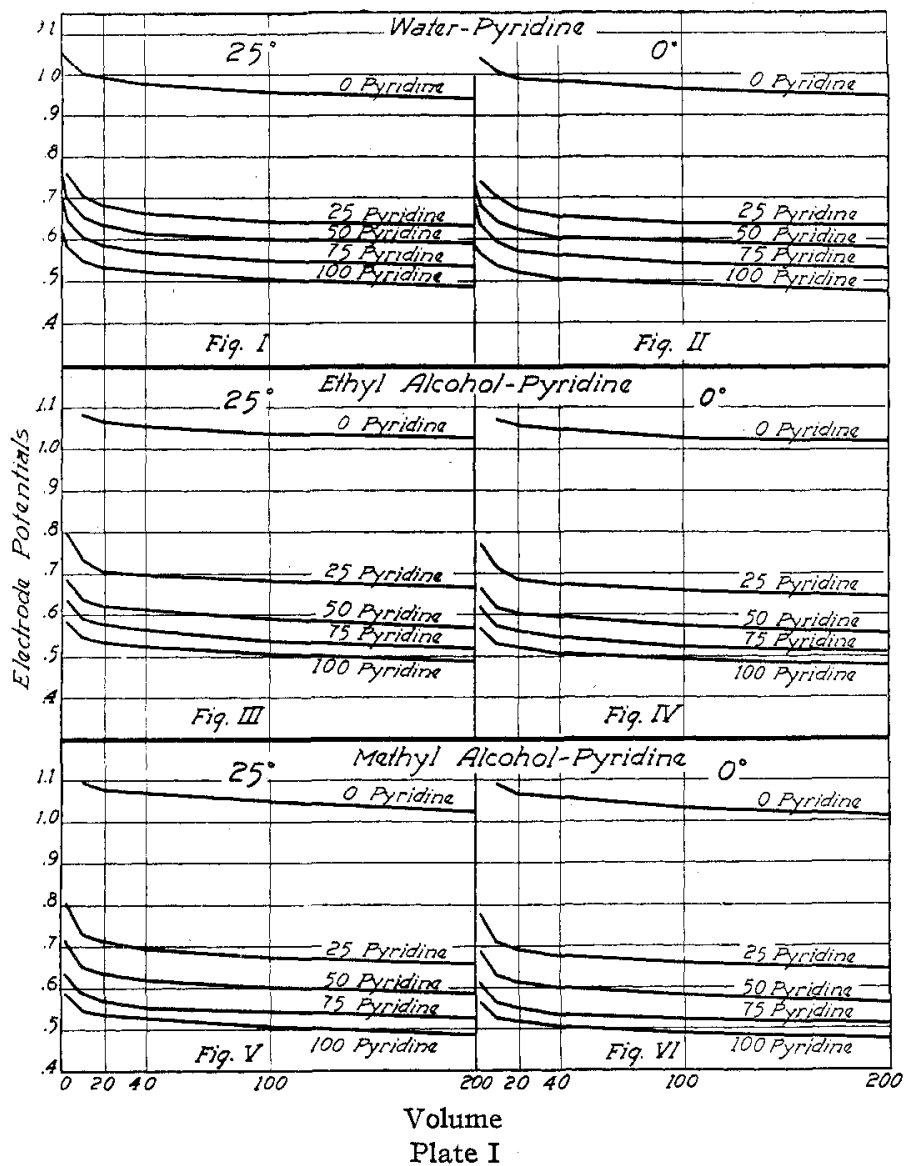

For all solvents, simple and mixed, the electrode potentials increase with increasing concentration of the dissolved salt. From the curves (Plate I) it will be observed that, starting with the most concentrated solution, the electrode potential drops

${ }^{1}$ Jour. Chem. Soc., 93, 549 (I908). 
very rapidly with the first dilutions and then decreases almost linearly with the dilution in the more dilute solutions. It will also be observed from the volume-electrode potential curves for any set of binary mixtures and, hence, for all pure solvents as well, that the curves obtained are, within limits of experimental error, practically parallel with each other. This confirms the relation pointed out by Farr." "If the electromotive force at the junction of the two solutions is entirely eliminated, and since the electromotive force of a concentration cell at a given temperature is proportional to the logarithm of the ratio of the ionic concentrations in the two solutions, it follows that the ratio between the ionic concentrations for equivalent concentrations of the salt in the separate solvents is constant and independent of the dilution."

The electromotive forces of all the possible concentration cells in each of the simple and mixed solvents were determined immediately after the readings for the electrode potentials had been made. The electromotive forces calculated for the concentration cells in the pure solvents--water, methyl alcohol and ethyl alcohol--agree closely with those determined by experiment. This confirms the statement made by Farr ${ }^{1}$ that the Nernst equation does hold for concentration cells in these solvents.

For solutions in pure pyridine, however, the values calculated for the concentration cells from conductivity data do not even approximate the electromotive forces experimentally determined. For all concentration cells where the normal solution constitutes one-half of the cell, the calculated values are smaller, whereas when the concentrations in each of the half-cells are less than $0.5 \mathrm{~N}$, the calculated values are larger than those observed. These deviations were not found to be appreciably lessened when the conductance values are corrected for viscosity. All of which goes to prove that, in so far as pyridine solutions are concerned, one of two conditions exist. Either the Nernst equation does not hold for concentration cells in pyridine as solvent, or the

${ }^{1}$ Loc. cit. 
electrical conductivity of these solutions is in no sense a measure of the degree of dissociation. Evidence seems to point most strongly to the latter condition as the one which is the cause of these deviations.

Walden and Centnerszwer, ${ }^{1}$ using the boiling-point method, have found that the molecular weights of silver nitrate in dilute pyridine solutions are normal, while in the more concentrated solutions the molecular weight is greater than normal. This evidence of association does not necessarily exclude the presence of ionization. Since pyridine solutions show considerable conductivity, ions of some sort must be present. As was pointed out by Pearce ${ }^{2}$ the amount of polymerization of the solute need only be very slight in order to compensate for the effect due to ionization. When these two effects just balance each other the molecular weights will appear as normal.

Transference measurements in pyridine solutions made by Neustadt and $\mathrm{Abegg}^{3}$ showed that both the $\mathrm{Ag}^{+}$ion and the $\mathrm{NO}_{3}$ radicle migrate toward the cathode. They assumed that, if ionization does take place, it does so according to the equation

$$
(\mathrm{AgNO})_{2}=\stackrel{+}{\mathrm{Ag}_{2}}\left(\mathrm{NO}_{3}\right)+\overrightarrow{\mathrm{NO}}_{3} .
$$

That the simple $\mathrm{Ag}^{+}$ions are also present is not to be doubted. In all probability we are here dealing with a complex equilibrium; viz., the simple and polymerized solute molecules in equilibrium with each other and with their respective ions. Under such conditions it would be impossible to calculate the electromotive forces from conductivity data.

The temperature coefficients of the electrode potentials have been calculated for solutions in the pure and mixed solvents and they are inserted at the bottoms of the tables for the electrode potentials. Obviously the accuracy of the temperature coefficients depend to a large extent upon the

${ }^{1}$ Zeit. phys. Chem, 55, 32 I (1906).

2 Jour. Phys. Chem., 19, 30 (I9I4).

${ }^{3}$ Zeit. phys. Chem., 69, 486 (I9Io). 
accuracy attained in the potential measurements, a slight error in the latter being enormously enhanced when it appears in the temperature coefficient. All of the temperature coefficients are positive except those in the more dilute aqueous solutions. At concentrations slightly greater than

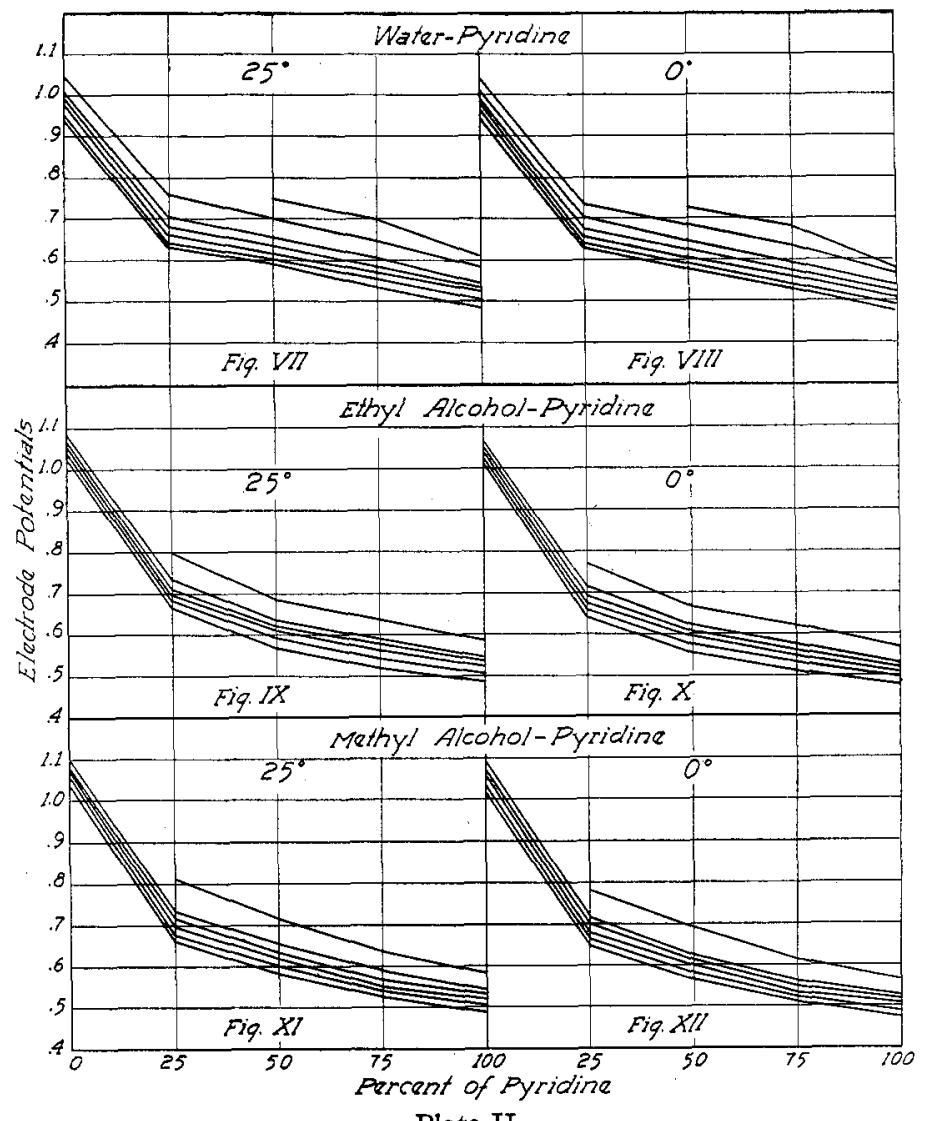

Plate II

o. Io $N$ the temperature coefficients in the aqueous solutions become positive. In all solutions containing pyridine the temperature coefficients are extraordinarily high. In the water-pyridine series they increase regularly from the value in pure water up to the value in pure pyridine. In the methyl alcohol-pyridine series these coefficients increase rapidly to 
a maximum value in the fifty percent solvent mixture, then decrease slowly to the value in pyridine. A similar relation is found for the binary mixtures of ethyl alcohol and pyridine except that the maximum occurs in the presence of a smaller percent of pyridine.

The heats of ionization are given in Table VII. They were calculated by substituting the mean temperature coefficients and the corresponding electrode potentials of the o. $\operatorname{Io} N$ solutions in Equation 5. The heat of ionization of silver in pyridine is relatively very low. For any series of solvent mixtures the heat of ionization decreases the most rapidly upon the first addition of pyridine to the second solvent, and then more slowly as the percent of pyridine is increased. The heat of ionization decreases with increase in the proportion of pyridine relatively more rapidly in each of the alcoholic pyridine series than in that of water and pyridine.

In the last column of Table VII are inserted a few dielectric constants. ${ }^{1}$ Here again it will be observed that the first addition of pyridine to the second solvent produces relatively the greatest change in the dielectric constant.

The solution pressure of silver in contact with pyridine solutions of silver ions is found to be much higher than when in contact with aqueous or alcoholic solutions. These pressures were calculated by making the proper substitutions in Equation 6, using in each case the value of the electrode potential found for the o.ro $N$ solutions. The values of $\alpha$ were calculated from the following conductivity data:

\begin{tabular}{l|c|c}
\hline \multicolumn{1}{c|}{ Solvent } & $\lambda_{10}$ & $\lambda_{\infty}$ \\
\cline { 2 - 3 } Water & $94.96^{2}$ & $\mathrm{I28.54^{3 }}$ \\
Methyl alcohol & $38.58^{2}$ & $98.00^{4}$ \\
Ethyl alcohol & $13.2 \mathrm{I}^{2}$ & $35.60^{3}$ \\
Pyridine & $27.58^{5}$ & $71.00^{5}$
\end{tabular}

${ }^{1}$ Determined by Mr. Richard Beeson, Drude-Schmidt method.

2 Jones and Bassett: Am. Chem. Jour., 32, 409 (r904).

${ }^{3}$ Kohlrausch, Sitzungsber. Berl. Akad., 26, 570 (Igo2).

4 Vollmer: Loc. cit.

${ }^{5}$ H. L. Dunlap (this laboratory). 
The solution pressures in water and the alcohols are in good agreement with those calculated by Farr. ${ }^{1}$ The value calculated for water is also very close to the value, $2.3 \times 10^{-17}$, found by Neumann. Assuming from conductivity data that silver nitrate is only one-fourth as highly ionized in pyridine as in water solutions, Kahlenberg. calculated the solution pressure of silver in pyridine to be $3.4 \times \mathrm{ro}^{-10}$. The value found in this work is $1.77 \times \mathrm{ro}^{-10}$.

The State University of Iowa

${ }^{1}$ Loc. cit. 